\title{
Finite Element Analysis of Universal Joint
}

\author{
${ }^{1}$ Swati N. Datey, ${ }^{2}$ S.D. Khamankar, ${ }^{3}$ Harshal C. Kuttarmare \\ ${ }^{I}$ (Lecturer) Mechanical Department Datta Meghe Institute of Engg.Technology \& Research \\ Sawangi Meghe, Wardha. \\ ${ }_{2}^{2}$ (Associate Professor) Mechanical Departmentm R.C.E.R.T, Chandrapur. \\ ${ }^{3}$ (Assistant Professor) Mechanical Department Datta Meghe Institute of Engg.Technology \& Research \\ Sawangi Meghe, Wardha.
}

\begin{abstract}
The power produced from an engine of automobile can be transferred to the drive wheel by power transmission system. Each automobile has different power transmission system constructive features depend on vehicle's driveline concept. While transmitting a torque different stresses are induced such as tensional stress \& bending stress are experienced. Finite element method is used as stress analysis to determine the stress conditions at a failed section.

In this preproject seminar report, analysis of rigid flange coupling is carried out which is similar to the universal joint. In this Finite Element Method analysis of rigid flange coupling with the help of ANSYS Software for different torque and load condition and it verify by manual calculation.
\end{abstract}

Index term: $C V$, ANSYS, FEM,

\section{Introduction}

The power produced from an engine of automobile can be transferred to the drive wheel by power transmission system. Each automobile has different power transmission system constructive features depend on the vehicle's driveline concept. (H.Bayrakceken et al., 2006) To transmit the driving torque from the engine or gear unit to the wheels, most of passenger car and light vehicle driven by combustion engine has at least two driveshaft as a basic requirement (Amborn, P. 1995). During operation, torsional stress and bending stress was experienced by driveshaft due to the weight of the car or misalignment of journal bearing (Asi, 2006). In order to meet the requirements of one of the most highly stressed components in automotive assembly, a failure investigation must be conducted. Finite element method was used as stress analysis to determine the stress conditions at the failed section. Nearly all of driveshaft are metal shafts or metal tubes that has special joint at each end called universal joint (Birch and Rockwood2005). Power transmission system of vehicles consist several components which sometimes encounter unfortunate failures. Some common reasons for the failures may be manufacturing and design faults, maintenance faults, raw material faults, material processing faults as well as the user originated faults. In this study, fracture analysis of a universal joint yoke and a drive shaft of an automobile power transmission system are carried out. Spectroscopic analyses, metallographic analyses and hardness measurements are carried out for each part. For the determination of stress conditions at the failed section, stress analysis is also carried out by the finite element method. The common failure types in automobiles and revealed that the failures in the transmission system elements cover $1 / 4$ of all the automobile failures. Some common reasons for the failures may be manufacturing and design faults, maintenance faults, raw material faults as well as the user originated faults.

\subsection{Types Of Universal Joint}

1. Normal universal joints (Cardan Joints)

2. Double universal joints (Double Cardan Joints)

\section{Cardan Joint}

A universal joint, universal coupling, U-joint, Cardan joint, Hardy-Spicer joint, or Hooke's joint is a joint or coupling in a rigid rod that allows the rod to 'bend' in any direction, and is commonly used in shafts that transmit rotary motion. It consists of a pair of hinges located close together, oriented at $90^{\circ}$ to each other, connected by a cross shaft

\section{Double Cardan Joint}

A double cardan joint consists of two universal joints mounted back to back with a center yoke; the center yoke replaces the intermediate shaft. Provided that the angle between the input shaft and center yoke is equal to the angle between the center yoke and the output shaft, the second cardan joint will cancel the velocity errors introduced by the first cardan joint and the aligned double cardan joint will act as a CV joint. 


\subsection{Identification Of Problem}

Drive shafts are one of the most important components in vehicles. It generally subjected to torsional Stress and bending stress due to weights of components. Thus, these rotating components are susceptible to fatigue by the nature of their operation. Common sign of driveshaft failure is vibration or shudder during operation. Driveshaft mainly involves in steering operation of vehicle. Drivers will lose control of their vehicle if the drive shafts broke during high speed cornering. Because of this human life can be in great danger if we don't know when, where and how the drive shaft will failed. It is very important to know the accurate prediction for the drive shaft to fail.

\subsection{AIMS AND OBJECTIVES}

The aim of the project is to study the stress distribution pattern of the rigid flame coupling by FEM using ANSYS and verification of result by analytical approach.

\section{- Design of universal joint}

The objectives of the project include modeling with help of CATIA. A universal joint (U-joint) is a joint in a rigid rod that permits the rod to move up and down while spinning in order to transmit power by changing the angle between the transmission output shaft and the driveshaft. A basic U-joint consists of driving yoke, driven yoke, spider and trunnions.

\section{- Analysis of universal joint}

Finite element method (FEM) is important numerical technique used in engineering analyses. Usually elements are sub-divided uniformly in FEM to obtain a fair solution with required accuracy. The procedure for solving the problem is-

(1) Create the geometry

(2) Set the material properties and boundary conditions.

(3) Mesh the domain

\section{- Analysis of universal joint by varying angle and torque}

Result comparison of different torque is done by ANSYS software. The effect of the geometrical parameters on the modal parameters of the system is presented. Results of some of the particular examples cases are compared and validated using general purpose finite element software.

\subsection{Scope And Approch}

In the project work design of universal joint is proposed. Further analysis on universal joint is done by varying angle and torque by using relevant soft-wares.

\subsection{Methodology}

The stress analysis of rigid flange coupling will be carried out as follows:

1. The CAD models of rigid flange coupling will be prepared in Pro-E software.

2. Stress analysis of each part will be done by Finite Element Method using ANSYS.

3. Analytical analysis will be done for each part and result will be computed.

4. Induced stresses obtained from analytical calculations will be compared with the results obtained by FEM.

\section{Literature Review}

\section{torque condition}

Siraj MohammadAli Sheikh $\{1\}$ In this paper titled analysis of universal coupling under different

Drive shafts are one of the most important components in vehicles. It generally subjected to torsional Stress and bending stress due to weights of components. Thus, these rotating components are susceptible to fatigue by the nature of their operation. Common sign of driveshaft failure is vibration or shudder during operation. Driveshaft mainly involves in steering operation of vehicle. Drivers will lose control of their vehicle if the drive shafts broke during high speed cornering. Because of this human life can be in great danger if we don't know when, where and how the drive shaft will failed. It is very important to know the accurate prediction for the drive shaft to fail. 
N. Cristello and I.Y. Kim (Canada) \{2\} In this paper titled Design Optimization of an Automotive Universal Joint Considering Manufacturing Cost

In this research, universal joint designs are analyzed and compared using a weighted sum of three objective functions: minimization of machining cost, maximization of adjoining shaft joint angle, and minimization of total part volume.

Vishal Rathi, N. K. Mandavgade $\{3\}$ In this paper titled FEM Analysis of Universal Joint of TATA 407 Traditional design has been done by simple calculation. But with increase in product performance and reliability it is difficult to follow the traditional iterative design procedures. To satisfy the market needs it is necessary to provide a computational capacity along with the creativity of the human being. A widely used numerical method for solving structural problems in both industry and academia is "FINITE ELEMENT METHOD. For effective and efficient FEM analysis the software should have: 1. Pre processor 2. Solver 3. Post processor Thermal analysis to calculate For finite element Analysis of Propeller Shaft \&Universal joint, SOLID92-Tetrahedral element has been used. the heat flux, temperature gradient $\&$ temperature variation in the structural and thermal aspects in case of Universal Joints.

\subsection{John R. Dharte $\{4\}$ in this paper titled Universal Joint Grease Development}

A project was conducted where different types of greases with different additives were evaluated in an effort to determine if performance improvements could be obtained in the universal joint application. Several different types of greases, calcium, lithium, lithium complex and polyurea were evaluated and compared to the current universal joint grease. The required grease for a universal joint must be a maintenance free grease that is used in a full complement of needle bearings.

3.5 Iqbal, J. and Qatu, M \{5\} in this paper titled "Vibration Analysis of a Three-Piece Automotive Shaft Drive shafts are major automotive components in rear wheel and four wheel drive vehicles. They can be made of single or multi-piece segments. The segments of a multi-piece driveshaft in automotive applications are joined using constant velocity or universal joints or a combination of frequency. This paper uses an exact solution for the vibration of a three-piece driveshaft with multiple intermediate joints. The joint is modeled as a frictionless internal hinge. Thin beam theory is used.elements). The solution should be of value to engineers interested in the design and optimization of the system.

\section{Case Study On Rigid Flange Coupling}

Shafts are usually available up to 7 meters length due to inconvenience in transport, in order to have a greater length, it becomes necessary to join two or more pieces of the shaft by means of a coupling, Shaft coupling are used in machinery for several purposes, the most common of which are the following:

1. To provide for the connection of shaft of units that is manufactured separately such as a motor and generator and to provide for disconnection for repairs or alternations.

2. To provide for misalignment of the shaft or to introduce mechanical flexibility.

3. To reduce the transmission of shock loads from one shaft to another.

4. To introduce protection against overloads.

5. It should have no projecting parts.

\subsection{Analytical Stress Calculation Of Rigid Flange Coupling}

- Design \& draw a cast iron flange coupling for a mild steel shaft transmitting $90 \mathrm{Kw}$ at $250 \mathrm{rpm}$. The allowable shear stress in the shaft is $40 \mathrm{Mpa}$ and the diameter of shaft is $80 \mathrm{~mm}$. calculate different Given data, stresses in it.

$\mathrm{P}=90 \mathrm{kw}$

$\mathrm{N}=250 \mathrm{rpm}$

$\mathrm{d}=80 \mathrm{~mm}$

The torque transmitted by shaft;

$\mathrm{T}=(\mathrm{p} * 60) /(2 \pi \mathrm{N})$

$=\left(90 * 10^{\wedge} 3 * 60\right) /(2 \pi * 250)$

$=3440 * 10^{\wedge} 3 \mathrm{~N}-\mathrm{mm}$

Considering strength of the shaft, we know that,

$(\mathrm{T} / \mathrm{J})=\left(\mathrm{T}_{\mathrm{s}} /(\mathrm{d} / 2)\right)$

$\left(\left(3440 * 10^{\wedge} 3\right) /\left((\pi / 32) * 80^{\wedge} 4\right)=\left(\mathrm{T}_{\mathrm{s}} /(80 / 2)\right)\right.$

$\mathrm{T}_{\mathrm{s}}=34.21 \mathrm{MPa}$ (shear stress induced in shaft)

Since the induced shear stress in the shaft is less than $40 \mathrm{Mpa}$ therefore the design is safe 


\section{Design for hub,}

Outer dia. Of hub $=2 \mathrm{~d}=160 \mathrm{~mm}$

Length of hub $=\mathrm{L}=120 \mathrm{~mm}$

Shear stress induced in hub by considering it as hollow shaft.

$\mathrm{T}=\pi / 16^{*} \mathrm{~T}_{\mathrm{s}}\left(\left(\mathrm{D}^{\wedge} 4-\mathrm{d}^{\wedge} 4\right) / \mathrm{D}\right)$

$3440^{*} 10^{\wedge} 3=\pi / 16^{*} \mathrm{~T}_{\mathrm{s}} *\left(\left(160^{\wedge} 4-120^{\wedge} 4\right) / 160\right)$

$\mathrm{T}_{\mathrm{sh}}=4.56 \mathrm{Mpa}$

Since the induced shear stress in the hub is less than $40 \mathrm{Mpa}$ therefore the design is safe

\section{Design for key}

Width of key $(\mathrm{w})=25 \mathrm{~mm}$

Thickness of key $(\mathrm{t})=14 \mathrm{~mm}$

Length of key $(\mathrm{l})=\mathrm{L}=120$

$\mathrm{T}=1 * \mathrm{w}^{*} \mathrm{~T}_{\mathrm{sk}} *(\mathrm{~d} / 2)$

$3440 * 10^{\wedge} 3=120 * 25 * T_{\mathrm{sk}} * 40$

$\mathrm{T}_{\mathrm{sk}}=28.7 \mathrm{Mpa}$

Since the induced shear stress in the key is less than $40 \mathrm{Mpa}$ therefore the design is safe

\section{Design for flange}

Thickness of flange $\left(t_{\mathrm{f}}\right)=0.5 \mathrm{~d}=40$

Shear stress in flange

$\mathrm{T}=\left(\left(\pi^{*} \mathrm{D}^{\wedge} 2\right) / 2\right)^{*} \mathrm{t}_{\mathrm{f}}^{*} \mathrm{~T}_{\mathrm{sf}}$

$3440 * 10^{\wedge} 3=\left(\left(\pi^{*} 160^{\wedge} 2\right) / 2\right) * 40 * T_{\mathrm{sf}}$

$\mathrm{T}_{\mathrm{sf}}=2.14 \mathrm{Mpa}$

Since the induced shear stress in the flange is less than $40 \mathrm{Mpa}$ therefore the design is safe

\section{Design for bolt,}

$\mathrm{d}_{1}=$ nominal dai. Of bolt $=18 \mathrm{~mm}$

since the dai, of the shaft is $80 \mathrm{~mm}$

let number of bolts $(\mathrm{n})=4 \&$

pitch circle dai. Of bolt $\left(D_{1}\right)=3 * d=240 \mathrm{~mm}$

the bolt are subjected to shear stress due to torque transmitted

$\mathrm{T}=(\pi / 4) * \mathrm{~d}_{1} \wedge 2 * \mathrm{n} * \mathrm{~T}_{\mathrm{sb}} *\left(\mathrm{D}_{1} / 2\right)$

$3440 * 10^{\wedge} 3=(\pi / 4) * 18^{\wedge} 2 * 4 * T_{\mathrm{sb}} *(240 / 2)$

$\mathrm{T}_{\mathrm{sb}}=28.16 \mathrm{Mpa}$

Other proportion of the flange are taken as follows

Outer diameter of the flange D2 $=4 \mathrm{~d}=4 * 80=320 \mathrm{~mm}$

Thickness of protective circumferential flange

$\mathrm{Tp}=0.25 \mathrm{~d}=0.25 * 80=20 \mathrm{~mm}$

\section{Steps Of Fem Analysis Using Ansys Is Given Below}

\section{Step 1}

\subsection{Modelling}

A CAD model of a rigid flange coupling is prepared in Pro-Engineer Wildfire 5.0 as per the dimensions used. This model of rigid flange coupling is shown in fig.

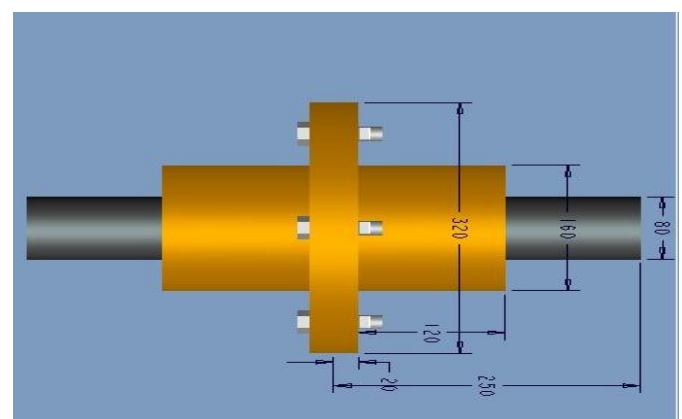

Fig. No.1 CAD Model 
Step 2

Imported Geometry In Ansys Workbench

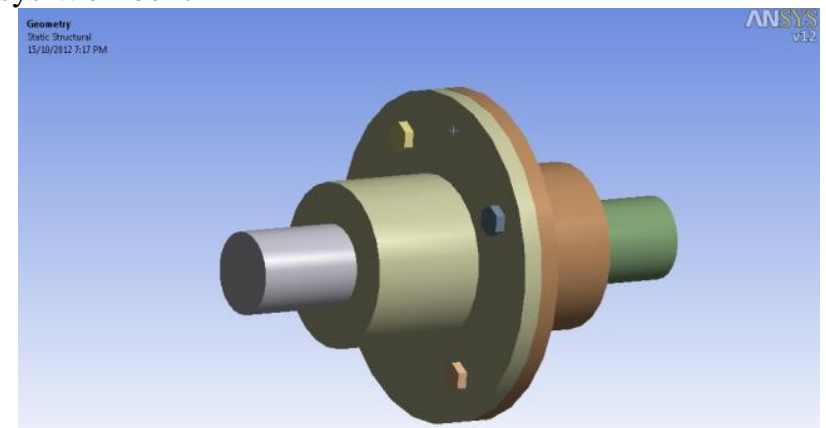

Fig. No.2 The model prepared in Pro-E is imported in ANSYS

Step 3 Meshing Of Model

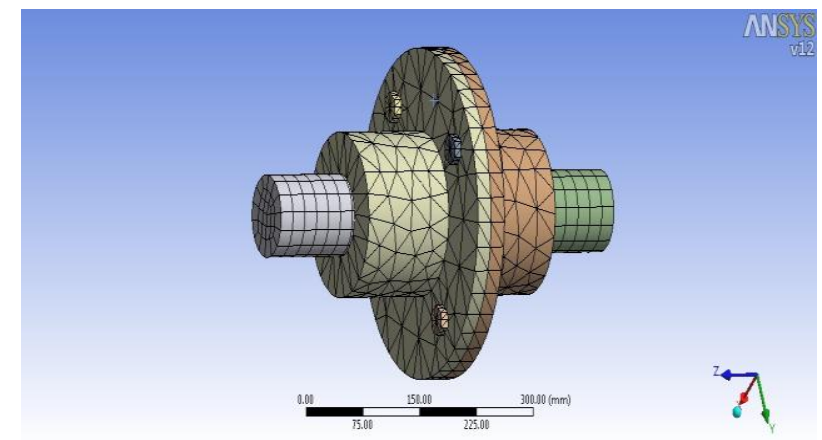

Fig No. 3 meshing of model

Step 4

Model With Boundry Conditions

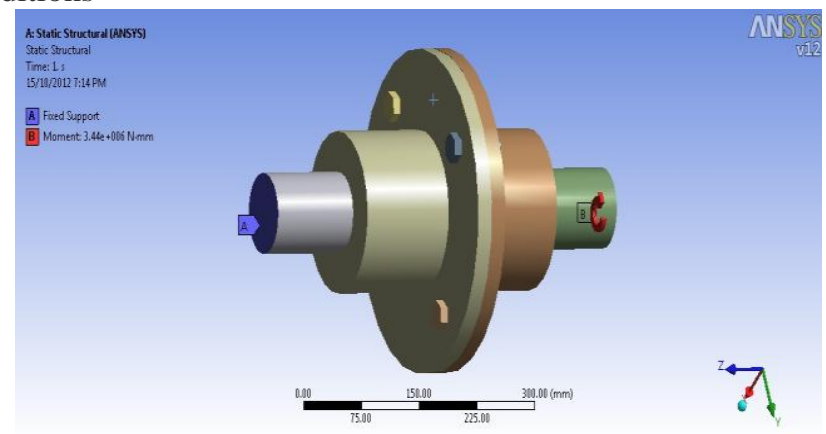

Fig No. 4 Applying boundary condition

Applying constraints/boundry condition on the geometry and giving torque of $3.44 * 10^{6} \mathrm{~N}-$

Step 5stress Pattern After Torque Application

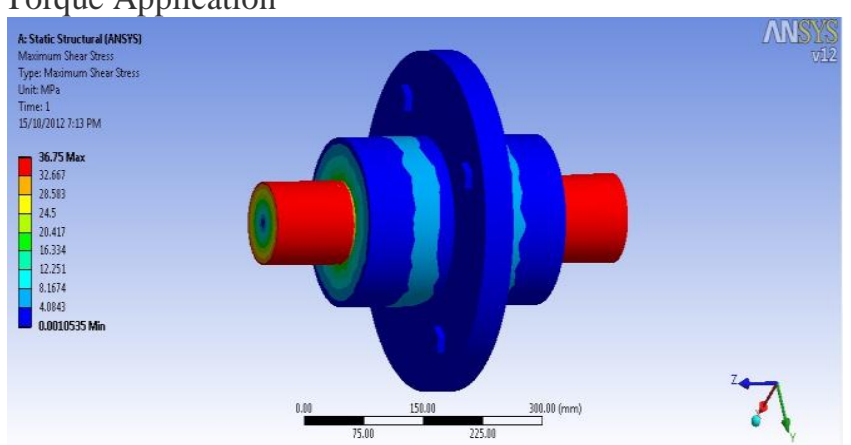

Fig. No. 5 Stress analysis obtained after applying the torque is as shown figure. 
From this analytical and practical result of ANSYS we are found the sheer stress in flange coupling.

\section{Future Scope}

1) By using same approach we will go to find out the shear stress in universal coupling.

2) By using different material we will find out the shear stress results and compare with analytical result.

3) At the various load condition we will take the result of shear stress on universal coupling and compare with the above condition.

4)

\section{Conclusion}

Comparing analytical and FEM result It is conclude that our design is safe because allowable shear stress is greater than the calculated shear stress.

\begin{tabular}{|l|l|l|}
\hline $\begin{array}{l}\text { TORQUE } \\
\text { APPLIED }\end{array}$ & ANAYLITICAL REASULT & FEM REASULT \\
\hline $\begin{array}{l}3.44 \times 10^{6} \quad \mathrm{~N}- \\
\mathrm{mm}\end{array}$ & $34.21 \mathrm{MPa}$ & $36.75 \mathrm{MPa}$ \\
\hline
\end{tabular}

References

[1] SAE Technical Paper 2002-01-0299, 2002, doi:10.4271/2002-01-0299.John R. Dharte - American Axle and Manufacturing

[2] SAE Technical Paper 2009-01-2067, 2009, doi:10.4271/2009-01-2067. Javed Iqbal - Oakland Univ.

[3] [IJESAT] INTERNATIONAL JOURNAL OF ENGINEERING SCIENCE \& ADVANCED TECHNOLOGY Volume-2, Issue-3, 690 - 694 ISSN: 2250-3676 Prof. Siraj MohammdAli Sheikh

[4] Rao, S. S. The Finite Element Method in Engineering", Second Edition, Elmsford, NY: Pergamon, 1989.

[5] J.H. Ong, "Finite elements for vibration of vehicle transmission system" Elsevier Science Publishers 1992, pp257-263

[6] Vogwell J. "Analysis of a vehicle wheel shaft failure" Eng Fail Anal 1998 